\title{
De los «desarreglados monstruos» a la estética del fracaso (Prehistoria del drama romántico) ${ }^{1}$
}

CÉsAR ReAl RAMOS

Universidad de Salamanca

«La historia del arte, entendida en su más amplia expresión para incluir en ella la literatura y la música, es tratada habitualmente con independencia de las condiciones históricas en que se produce, y su estudio, entendido como el desarrollo autónomo, de las formas y estilos artísticos. La superación de semejante limitación exigiría una mayor interpenetración de las disciplinas que tienen un común planteamiento histórico, para poner en evidencia la relación que existe entre los diversos fénóménos de una misma época» ${ }^{2}$.

1 Tomamos el término de «prehistoria» del artículo del profesor Hans Ulrich Gumbrecht "Ce sentiment de douloureux plaisir, qu'on recherche, quoiqu'on s'en plaigne», donde se aplica al teatro parisiense de Thermidor 1794 a Brumaire 1799, en Romanistische Zeitschrift für Literaturgeschichte, 3/4, Heidelberg, 1979, pp. 335-373.

2 Miguel Artola, La burguesía revolucionaria (1808-1874), Alfaguara (7. a ed.), Madrid, 1980 , p. 355. 


\section{Propósito}

A esta limitación transcrita, de un estudio de la literatura (o del arte) sin conexión con otros fenómenos sociales, habría que añadir la tendencia a enjuiciar tan sólo aquellas obras que desde nuestra actual perspectiva merecen una mejor consideración estética, olvidándonos del aprecio y la repercusión que entre sus contemporáneos adquirieron muchas otras y desdeñando su importancia en el desarrollo de la historia literaria, de la historia de las ideas y de esa historia «general» que habría de dar cabida a todo planteamiento histórico. Ello se hace especialmente patente en el caso de la «literatura» de que hoy nos ocupamos, no por menos literaria indigna de nuestra atención, y cuyo descuido, entre otros muchos factores, ha llevado por lo común a afirmar una tan sorprendentemente tardía y repentina como efímera manifestación del Romanticismo español en nuestra escena. A ello se suma que la intelligentsia de la época, tan asidua como despreocupada o desdeñosa de las monstruosas piezas que invadían nuestras tablas, nos ha legado una controversia en tan estrechos cauces que aún la crítica de hoy día se empeña en dilucidär si el romanticismo lo llevamos los españoles en la sangre o es la esencia de nuestras mejores obras que vuelve a florecer tras el imperio del «buen gusto».

El clamoroso éxito que inmediatamente alcanza el drama romántico desde 1834 y su carácter más evasivo en relación con la comedia moratiniana (como prueba la reaccionaria prohibición de esta última) nos hacen poner en duda las causas meramente políticas - la muerte de Fernando VII, sobre todo-como únicas determinantes de su triunfo, para tratar de encontrar aquellos antecedentes que justifican el nacimiento y desarrollo de sus propias características dramáticas y del gusto del público por ellas. En tal intento, dedicamos estas páginas a ese espacio vacío de nuestras historias literarias, poblado por obras en las que predominan otras funciones sobre la puramente literaria, que no son neoclásicas, ni romáticas, ni frecuentemente españolas (ergo sobran), pero que vivifican una de las instituciones indudablemente más significativas y más determinantes de nuestra historia contemporánea: el teatro decimonónico.

«Lo que de otra manera nunca podría haber visto»

El lento desarrollo de la escena española hasta la aparición del drama romántico se hace incomprensible, a nuestro entender, si saltándo- 
nos a la torera el género durante todo el siglo XVIII más aplaudido y frecuentado - la comedia de teatro- tratamos de remontarnos a nuestra época áurea. Tal es, sin embargo, la actitud más frecuente, derivada asimismo del lógico y común desprestigio de la comedia de teatro entre los dos eruditos bandos que a partir de la publicación de las reflexiones de Schlegel se enfrentaron públicamente ${ }^{3}$. Sin negar ciertas evidentes concomitancias entre el Romanticismo y nuestros escritores barrocos (que desde luego van mucho más allá de la falta de respeto a las reglas; aún está por explorar en qué medida se trata de una influencia indirecta a través de las obras traducidas), habría que convenir con Alcalá Galiano en que «si entre ellos hubo escritores románticos, lo eran al modo del famoso monsieur Jourdain de Molière». La distancia entre nuestro Barroco y nuestro Romanticismo se puede además apreciar en sus justos límites ateniéndonos a la progresiva decadencia del drama áureo durante el siglo XVIII, como demuestra René Andioc, en la que la prohibición de los autos sacramentales apenas tuvo repercusión significativa ${ }^{4}$.

La comedia de teatro, género establecido por Luzán en la clasificación de la obra de Calderón, se basa en el predominio de la fantasía y el «coup de théâtre», exigiendo su adaptación una desarrollada tramoya que encarece los costos de escenificación y, en consecuencia, el precio de las entradas, lo cual no fue óbice para que se constituyera hasta ya avanzado el siglo XIX, como se ha señalado, en el mayor foco de interés no sólo de las capas de baja extracción social ${ }^{5}$. Arraigada, así pues, en la comedia barroca, abarcando diferentes subgéneros normalmente híbridos y emparentados entre sí, incluso en su paternidad artística, fue el primer monstruo al que tuvo que hacer frente el minoritario grupo

3 Las directrices fundamentales de nuestra controversia, así como la remisión del concepto de Romanticismo a épocas anteriores, sin ajustarlo a la definición del nuevo movimiento (lo que hoy dia nos puede resultar operativo), nos fueron igualmente legadas de la polémica suscitada en otros países. Al respecto véase René Wellek, «El concepto de romanticismo en la historia literaria», Conceptos de critica literaria, Ed. de la Biblioteca de la Universidad Central de Venezuela, Caracas, 1968, pp. 103-153.

4 R. Andioc, Teatro y sociedad en el Madrid del siglo XVIII, Ed. Castalia, Madrid, 1976.

5 «... máquinas destinadas a que los personajes o los objetos se burlen de las leyes de la gravedad: los protagonistas suben por los aires o desaparecen bajo la tierra; carros, naves, e incluso palacios y montes evolucionan por encima del escenario.» R. Andioc, ibid., p. 51.

J. Campos, en su obra Teatro y sociedad en España (1780-1820), Ed. Moneda y Crédito, Madrid, 1969, p. 205, nos relata la afición de Fernando VII a las comedias de magia. 
que trató de imponer una comedia arreglada y didáctica ${ }^{6}$. Lo interesante en este género no es sólo su enorme éxito, sino que son las mismas obras las que una y otra vez son repuestas y aplaudidas (frente a, como veremos, la efímera duración en cartel de piezas de géneros posteriores). Ello pone de relieve aún más esta importancia del aspecto espectacular que siempre podía ser nuevo. Nunca quizás desde la época del Mio Cid las expectativas textuales fueron menores.

Aparte de este rasgo característico que herederá parte del teatro posterior no neoclásico, de esta capacidad de provocar la admiración y la ilusión del público, trasponiendo a las tablas las escenas más espectaculares de la vida cotidiana del pueblo madrileño (desfiles, ejecuciones, fuegos artificiales...) o «lo que de otra manera nunca podría haber visto» (hechos fabulosos, maravillosos, sobrenaturales), muchos otros elementos se perciben como precursores del movimiento romántico: la posibilidad de superación de las desigualdades sociales (aunque sea por la magia), cierto realismo sádico (abundante incluso en las comedias de santos), la multiplicación de vicisitudes en el desarrollo de la acción, la frecuente ambientación exótica y, sobre todo, esta primacía temática de lo mágico y lo oculto ${ }^{7}$. Pero quizás lo más interesante, y en ello no se suele insistir suficientemente, es el paradójico hecho de que este tipo de comedia desempeñó una función ilustradora considerable al contribuir a «deshacer prejuicios, supersticiones y fábulas, que habían sumido en el terror a gentes de distinto pelaje en tiempos anteriores» ${ }^{8}$.

De entre sus diferentes subgéneros es especialmente significativa esta función en la comedia "de figurón», en la que a través de este cómico personaje se burla el espectador de los caracteres que representa: la credulidad, la rudeza, la simpleza y la mentalidad rancia y conservadora. En cierto sentido, resulta una comedia de caracteres (si bien se

6 En su Teatro popular y magia, Rev. de Occidente, Madrid, 1974, p. 43, Julio Caro Baroja señala ya El jardín de Falerina, zarzuela en dos jornadas de Calderón (1648), como auténtica obra de magia por sus transformaciones, hechizos y contrahechizos.

7 Sería arriesgado tratar de justificar de forma rotunda el éxito de este tipo de teatro. R. Andioc, en la obra citada, p. 97, atribuye al espectador la «ilusión de una realización total de su ser, de una plenitud que le niega el orden social vigente». Personalmente, nos parece igualmente relevante el hecho de que este género se desarrolle en el «Siglo de la Razón».

El título con que encabezamos este apartado lo tomamos de un programa de televisión sobre el éxito actual del cine de ciencia-ficción, cuyo parecido resulta enormemente sugestivo.

8 J. Caro Baroja, op. cit., p. 240. Es significativo que el autor nos indique que se acerca a este género más por intereses culturales que simplemente literarios. 
trata siempre del mismo tipo social) y, como señala Caro Baroja, representa un interesante signo de los tiempos ${ }^{9}$.

De todo ello resulta, pues, que el ataque neoclásico a este tipo de teatro, llevado a cabo no sólo desde la tribuna de las publicaciones periódicas, sino incluso a través de los intentos de reforma (encareciendo el precio de sus entradas o no autorizando su representación), al igual que la prohibición de los autos (y comedias de santos), revela no tanto razones ideológicas como meramente artísticas: estas obras no se ajustaban a las reglas, ni al buen gusto, ni al medio de persuasión (el raciocionio, no la emoción) pregonados por los que se querían únicos representantes de las luces. En otras palabras: se impuso el Neoclasicismo a la Ilustración. No es sorprendente que Werner Krauss nos diga que, a diferencia de otros países, en España la Ilustración europea no se realiza más que superficialmente, con una influencia de la nobleza (como modelo) en el pueblo y a la inversa, y con fuerte dependencia del poder del pensamiento católico ${ }^{10}$.

\section{Las lágrimas compasivas del «género serio»}

El desarrollo de esa gente ciudadana de que nos habla Caro Baroja, cuyos intereses no se verán reflejados en la comedia «de figurón», coincide con la aparición de un nuevo género ya alabado por Luzán: la comedia «lacrimosa» («llorosa», «urbana», «sentimental», «seria»...), que con el cambio de siglo alcanzará un éxito clamoroso haciendo verter muchísimas lágrimas a todo Madrid. De origen probablemente inglés, importada también de Alemania, siempre a través de Francia, e incluso de este último país, y aun cultivada por nuestros ingenios desde Jovellanos (aunque fuera entonces de modo circunstancial, para un certamen, y las obras de sus rivales no se publicaran, no estando aún formado el gusto hacia ellas), se aclimató pronto a nuestro suelo con el

9 «Personalmente creo que el "figurón" en el punto en que lo usan Zamora y Cañizares revela una realidad social nueva. Es como un signo de los tiempos. Y como tal signo podemos estudiarlo con una determinada vigencia temporal. En otras palabras, el "figurón", con el que se ridiculizan creencias determinadas a fines del XVII, se desarrolla en el siglo XVIII y muere ya avanzado el XIX: porque entonces ya lo que se ridiculiza en él no tiene para la gente ciudadana demasiado significado.» Ibíd., p. 140.

10 W. Krauss: Die Aufklärung in Spanien, Portugal und Lateinamerika, Wilhelm Fink Verlag, München, 1973.

Para Miguel Batllori lo que ocurre es una mayor duración de la Pre-llustración entre nosotros. Vide «Notas sobre la Iglesia en el siglo de la Ilustración», Historia $16,16-12-78, \mathrm{pp} .105$ y ss. 
beneplácito ilustrado, a veces algo a regañadientes, pero con el disgusto de nuestros clasicistas, quienes verán nacer aquí otros nuevos monstruos ${ }^{11}$.

El repaso de sus características dominantes nos permite comprender de inmediato las reacciones antes apuntadas. Como cuadro («tableau») y verdad («vérité») nos describe Peter Szondi los rasgos distintivos de este género, según los define Diderot en sus Entretiens, oponiendo al primer término el de «coup de théâtre»: «incidente imprevisto que ocurre en la acción y que cambia súbitamente el estado de los personajes» ${ }^{12}$. Ahora bien, la intriga, la imaginación y la peripecia eran intrínsecas al drama barroco, tan degustadas de los clasicistas como repudiadas de la estética neoclásica. Lo que ni unos ni otros acababan de aceptar era, por otra parte, el elemento determinante de su propio género: la compasión, sentimiento planteado en su propia estructura dramática que lo convertía en «comedia triste». En efecto, H. U. Gumbrecht nos presenta el "género serio» como el resultado de dos componentes estructurales: la recurrencia del actante central de la «vertu persécutée» y el «happy end». Puesto que la persecución que sufre la virtud es inmotivada, injustificada (no es el resultado de un delito cometido anteriormente) - nos sigue explicando-, despierta la compasión del espectador que, con el final feliz, en cuanto marco «ficcional» de dicho sentimiento, revierte sobre sí mismo en un acto de autorreflexión ${ }^{13}$. Este generoso sentimiento tiene como objeto, en último término, la identificación del espectador con el resto de sus congéneres, en cuanto hombre natural, según Mercier y Diderot, que la filosofía de la Ilustración opone a la corrupción social ${ }^{14}$. En este punto se nos presenta, pues, la comedia «lacrimosa» como un género ilustrado, pero por sus novedades quizás no tan neoclásico.

11 L. Pataky Kosove, The «Comedia lacrimosa» and Spanish Romantic Drama (1773-1865), Tamesis Books Limited, London, 1977, p. 26, señala Love's Last Shift, de Colley Cibber, como la primera del género.

Al respecto cita J. Campos del Arte de hablar en prosa y en verso de Hermosilla: «Mas insistiré en que no son comedias ni tragedias propiamente dichas, sino una clase media», op. cit., p. 108. Sobre la repulsa clasicista de estas monstruosas obras, ibid., p. 129.

12 Peter Szondi: «Tableau et coup de théâtre», Poétique, 9, 1972, p. 5. «L'imprévu était banni de la société bourgeoise du XVIIIe. siècle. L'éthique fondée sur la Raison, moment constitutif du capitalisme, tend à éliminer le hasard». Ibid. H. U. Gumbrecht, "Ce sentiment de douloureux plaisir...», loc. cit., pp. 340-341.

Ibid., p. 341, y en «Über das Versiegen süsser Tränen in der Französischen Revolution», del mismo, en Lendemains, 11 (1978), pp. 69-70, donde la separa de la función catártica propia de la tragedia. 
El «género serio», que huye del sicologismo por lo que éste tiene de invidualizante, se propone representar más bien funciones sociales (el comerciante, el finanćiero, el abogado, etc.), en lo que se puede aproximar a la comedia de costumbres y en lo que ha sido igualmente emparentado con el desarrollo de la burguesía urbana. Por lo que respecta a Madrid, sobre todo, la casi ausencia de industria, de un comercio importante, e incluso de muchas profesiones liberales hace presuponer más bien un propósito o un anhelo social que un reflejo del predominio de dicha burguesía ${ }^{15}$.

Aún más que estados y oficios le interesaban a Diderot las relaciones familiares, según Szondi, por cuanto la familia burguesa patriarcal era una garantía de felicidad como marca de lo privado frente a lo público; y aun diríamos natural frente a social ${ }^{16}$. En la intersección de ambos dominios (funciones sociales y relaciones familiares) se inscriben los temas - tan recurrentes en la comedia seria, aunque comunes a casi todos los géneros dramáticos coetáneos- del intento de promoción social y de la libertad de elección del cónyuge, o de las desavenencias matrimoniales (asunto preferido incluso de la prensa periódica) ${ }^{17}$.

Tanto en la función igualitaria que supone el desarrollo del sentimentalismo en cuanto compasión, como en la predilección por los personajes antes señalada o en la temática dominante, se advierte una actitud ilustrada prerromántica que ha sido a veces un tanto desenfocada ${ }^{18}$. A ello habría que añadir la frecuente profusión de ciertos elementos en algunas de las obras de este tipo: utilización de la pantomima como medio de transmisión del patetismo, estilo declamatorio, uso de la prosa "por más natural» que el verso, recurrencia a asuntos relacionados con los campos semánticos de lo lúgubre, lo misterioso, lo horroroso..., expresión por parte de algunos personajes de una visión pesimista del mundo, etc., que señalan no sólo el carácter prerrománti-

15 Vide G. Anes, El Antiguo régimen: los Borbones, Alfaguara, Madrid, 1979, respecto al desprestigio del comercio, p. 56; sobre la escasez de profesionales, ibid., página 91.

16 Cf. P. Szondi, loc. cit., p. 10.

17 Véase «La prensa», de L. M. Enciso y C. Almuiña Fernández, Historia $16, \mathrm{n} .{ }^{\circ}$ citado, p. 148.

18 Cuando Andioc señala la atenuación por cierta timidez o prudencia de la protesta que supone Ana y Sindhan, destacando una «actitud pasiva», o que en El amor $y$ la intriga se produce una revuelta del noble, pero no del pechero, tratando de explicar el posible menor éxito de las obras entre el pueblo bajo, no se da cuenta de que esa «actitud pasiva» de la virtud oprimida es indispensable al género: el medio de despertar la compasión. Cf. op. cit., pp. 111 y 113. 
co del género, sino su evolución hacia formas más próximas al Romanticismo, como veremos en el siguiente apartado. No creemos, sin embargo, que pueda aún hablarse de auténtico Romanticismo, teniendo a la vista los elementos ilustrados que hemos venido señalando y la ausencia en España de una ideología romántica, no ya a fines del XVIII y principios del XIX, sino casi hasta finales de este último siglo ${ }^{19}$.

\section{La estética del melodrama: asombrar, asustar, conmover}

Entre la perduración del "género serio», como forma no fosiliza$\mathrm{da}$, sino en continua transformación, que J. L. Pataky Kosove alarga hasta Cecilia la cieguecita (1843), la comedia «de teatro» (sobre todo, «de magia») y la comedia puramente neoclásica (en algún aspecto cercana a la «lacrimosa», como luego se verá), aparece en la escena española de los primeros decenios del XIX un nuevo tipo de piezas que poco a poco se irá adueñando de los repertorios teatrales, el melodrama, cuyo origen sitúa $H$. U. Gumbrecht ya con anterioridad a 1800 en el teatro «de boulevard» galo ${ }^{20}$. Nacido, pues, en un medio popular, comporta una serie de aspectos que lo hacen idóneo para el gusto del «vulgo» español: la combinación de partes musicales, tan significativa -aunque no exclusiva - del género, que permanece en su denominación; la espectacularidad aneja a la escenificación de sus frecuentes ajusticiamientos, tempestades, incendios y tantas otras calamidades ya degustadas, como se ha visto, desde antiguo; la superficialidad de los caracteres y la sencillez de su planteamiento dramático; la «democratización» de la temática y los personajes, que no son ya exclusivamente burgueses, como en el «género serio»; la recurrencia a un sentimiento tan igualitario como el miedo en las miras de su estrategia dramática; el rechazo de toda censura, posibilidad de decirlo todo, sin exclusión de la inverosimilitud, el crudo realismo, el fascinante poder del mal... ${ }^{21}$.

19 Vide M. Artola, op. cit., p. 330.

Nos parece excesiva, por tanto, la postura de Russell $P$. Sebold, quien ve un auténtico Romanticismo entre 1770 y 1800 (el fenómeno a partir de 1830 aproximadamente sería un «Romanticismo manierista»), que ilustra, entre otras obras, una de las de este género: El precipitado. Vide de dicho autor: «El incesto, el suicidio y el primer Romanticismo español», Hispanic Review, 41, n. ${ }^{\circ} 4$ (1973), pp. 669-692, y «Sobre el nombre español del dolòr romántico», Insula, n. ${ }^{\circ} 264$ (1968), pp. 1, 4 y 5, ahora recogidos en Trayectoria del Romanticismo español, Ed. Crítica, Barcelona, 1983.

20 Cf. «Ce sentiment de douloureux plaisir...», loc. cit., p. 356.

21 Vide Peter Brooks, «Une esthétique de l'étonnement: le mélodrame», Poétique, $\cdot 19,1974$, p. 353. 
El «punto focal» del melodrama, según P. Brooks, es la admiración de la virtud ${ }^{22}$. Esta, amenazada por el mal, deberá emprender un éxodo de su situación gozosa inicial, obstaculizado por las acciones de malignos personajes, infortunios y desastres naturales que revelan la acción de la Providencia, hasta el ultimísimo momento, que culminará el «happy end» resarciéndola y premiándola y castigando al malvado. Lo que importa subrayar es que, al igual que en el "género serio», a la persecución inmotivada, injustificada, se añade la resignación del personaje virtuoso, posibilitando la identificación del bien y el mal y el asombro que se produce cuando la moral se impone y se hace reconocer ${ }^{23}$. A esta identificación conduce igualmente una técnica enfatizante (carácter hiperbólico de los personajes, fraseología grandilocuente, simplicidad y carácter exagerado de los «signos», propensión de los personajes a expresar sus juicios morales sobre el mundo, que nos señala Brooks) que intenta evitar cualquier sombra que pueda entorpecer la clara visión de un mundo maniqueo. $Y$ en ello ve $P$. Brooks la función principal del género: en el redescubrimiento y la repetición de una moral soterrada «en un universo desacralizado donde los imperativos morales y claros compartidos por la comunidad se han perdido», revelando en último término el «verdadero drama (moral, cósmico)» desde el «drama aparente (naturalista, banal)» ${ }^{24}$. Es difícil, sin embargo, aceptar totalmente tal hipótesis en relación con nuestro país, donde una escasa ilustración, aliada con el catolicismo, no culmina en una revolución «desacralizadora» ${ }^{25}$. Hay, en efecto, una posible acción inculcadora de principios morales en el melodrama que ya apuntaba Nodier en 1841 al ocuparse del teatro de Pixérécourt que, tal vez (sería arriesgado establecer una estricta relación causa-efecto), determinó un comportamiento más civil del pueblo parisiense ${ }^{26}$. Sin embargo,

22 «Leur point focal peut être défini ici comme l'admiration de la vertu. Affrontement et péripétie sont concus pour rendre possible un hommage aussi spectaculaire que public à la vertu, pour mettre en évidence son pouvoir et ses effets.» Ibíd., página 341.

23 «Le mélodrame en général, non seulement se sert de la vertu persécutée comme ressort de la dramaturgie, mais tend à devenir la dramaturgie de la vertu méjugée et finalement reconnue.» Ibíd., p. 342.

24 Ibid., pp. 352-354.

25 «Cristianismo y Cultura Ilustrada no sólo coexisten paralelamente, sino que llegan a simbiotizarse en algunos de sús más insignes representantes». Miguel Batllori, «Notas sobre la Iglesia en el siglo de la Ilustración», loc. cit., p. 105.

26 «... il y avait dans l'application du mélodrame au développement des principes fondamentaux de toute espèce de civilisation, une vue providentielle [...] en aucun temps, la classe qui la subissait immédiatement n'a été plus régulière dans ses moeurs, jamais les crimes n'ont été plus rares.» Citado por Gumbrecht en «Ce sentiment...», loc. cit., p. 358. 
en el desarrollo predominante que adquiría el mal en el melodrama y en la fascinación que su desmesurado poder ejercía en el público - lo cual no escapa a los ojos de Brooks-, veían los críticos españoles contemporáneos más bien una posibilidad de emulación y, en consecuencia, un peligro social. Porque lo que esta nueva estética aportaba era la sustitución de la compasión como sentimiento predominante por el miedo, por el patetismo, por el «suspense», que diríamos hoy. No es ajeno el hecho de que, como a veces se ha advertido, sea frecuentemente el débil, el indefenso, quien encarne la virtud en estas obras (recurso, por otra parte, al que ya acudía Lope). Un miedo que no se justifica tan sólo en el vacío de terror dejado por los acontecimientos políticos recientemente acaecidos, sino que tiene razones más profundas, como ve el profesor Gumbrecht, que lo define como miedo abstracto («Objektlose Angst») y que el final feliz limita al marco ficcional; es la objetivación del rechazo del miedo de la comedia y de los discursos políticos, que con su retórica halagüeña encubren un mundo de enorme inestabilidad social. No es extraño, por tanto, que el drama romántico, que en tantos aspectos anticipa el melodrama (importancia del azar, la Providencia -el sino- en la acumulación de obstáculos y en el desarrollo de la intriga; dicotomía bien $/ \mathrm{mal}$, inocencia/perversidad; primacía del sentimentalismo, del patetismo...) sea años más tarde, con la supresión del «happy end» y del consuelo, la expresión del desencanto, de la frustración, del fracaso.

Queda únicamente por señalar que, a pesar de la enorme cantidad de melodramas que invaden nuestra escena, son éstos susceptibles en su mayoría no sólo de una descripción general, como aquí hemos pretendido, sino de ser analizados en una serie de mecanismos comunes (muchos de los cuales recogerá igualmente el drama romántico) mediante los cuales articulan esta estética del asombro y del miedo. El melodrama, por otra parte, permeable a los gustos y técnicas en boga, se convierte con frecuencia, en razón de su peculiar ejecución, en el género híbrido conocido como «melo-mimo-drama de gran espectáculo». El apelativo, de todas formas, no pasó de ser en muchos casos un reclamo publicitario.

\section{El teatro español hasta el triunfo romántico. Larra, un testigo de excepción}

Tras esbozar rápidamente aquellos tipos de comedia que, a nuestro entender, preludian de forma más nítida el drama romántico, tratamos a continuación de presentar la problemática concreta de nuestra 
escena en estos años anteriores a dicho triunfo. Creemos, sin embargo, que es difícil dar una visión clara de las diferentes tendencias que concurren en las escena española hasta la llegada del Romanticismo y de la respectiva importancia de cada una de ellas mientras no se lleve a cabo un análisis exhaustivo de las carteleras, ingresos proporcionados por las obras, duración de éstas, tipo de público que las frecuentaba, etc., tal como ha hecho R. Andioc respecto al teatro del XVIII, contradiciendo algunos lugares comunes (como el «creciente éxito del drama barroco») ${ }^{27}$. Tanto más cuanto, como veremos, los estudios parciales hasta ahora realizados no parecen concordar en muchos puntos.

Como ya se ha señalado, el teatro áureo no obtiene ni de lejos el éxito que se le suele atribuir durante el siglo XVIII. Si al paulatino decrecimiento de su importancia en las últimas décadas añadimos la prohibición de los autos y el desprestigio progresivo de las refundiciones, contra las que claman incluso los «barroquistas» -y que prácticamente desaparecen en los primeros años de los treinta, según muestra Rumeau-, habría que suponer que apenas incide en el nacimiento del drama romántico ${ }^{28}$. Por lo demás, como el mismo Andioc concluye tras el análisis de ingresos y precios de entradas, era éste, sobre todo, frecuentado por el público culto y pudiente, para el que, por otra parte, no ha perdido su vigencia en cuanto literatura, puesto que se sigue editando ${ }^{29}$. Su reivindicación por parte de los «romanticistas» durante la polémica no ha de entenderse, por tanto, como defensa de unos principios dramáticos vigentes, sino como búsqueda reaccionaria - paradójicamente por influencia extranjera - de un ideal de España que oponer al sistema estético y social que, por influencia extranjera, proclaman los ilustrados ${ }^{30}$. Es la pugna de doctos contra doctos, mien-

Así A. Peers, que sigue a Menéndez Pelayo, en Historia del movimiento romántico español, Gredos, Madrid, 1973, vol. I, pp. 101 y ss., insiste en un creciente exito del drama barroco y de Calderón para justificar el «renacimiento romántico». A. Rumeau, «Le théâtre à Madrid à la veille du Romantisme, 1831-1834», en Hommage a Ernst Martinenche, 1939, pp. 330-346. No deja de sorprender que, frente a Andioc, José Subirá señale entre los gustos predominantes del público en los años 1763-1771 a Lope, Calderón, Tirso, Moreto, Rojas Zorrilla y. Solís («Repertorio teatral madrileño", BRAE, n. ${ }^{\circ} 39,1959$, p. 460).

Como muestran los 16 vols. del Theatro Hespañol de García de la Huerta (17851786).

30 Guillermo Carnero, en Los orígenes del Romanticismo reaccionario español: el matrimonio Böhl de Faber, Univ. de Valencia 1978, p. 260, nos dice: «[...] para Böhl y compañía no se trata sólo de reivindicar en el dramaturgo la España del pasado, sino de dar pautas de "regeneración" para la del presente. En efecto: mientras los Ilustrados y Filósofos abogan por el progreso político y científico, nuestros calderonianos opinan que el futuro de España está en hacer que rebroten las 
tras el público (el pueblo) camina por muy otros derroteros. El terreno, por otra parte, era díficil para que floreciese el teatro neoclásico, con un público poco propicio a sus restricciones de la imaginación y de las posibilidades escénicas:

Escasos eran en verdad los frutos que esta nueva escuela brindaba a las lozanas e indomables imaginaciones españolas, acostumbradas a marchar libres de toda traba por el ameno y dilatado campo de la fantasía. Difícil empresa se presentaba ya la de hacer una comedia con un objeto filosófico, con caracteres verídicos, con situaciones y diálogos naturales, a los que estaban acostumbrados a producir a docenas los enredos fantásticos, los personajes hiperbólicos, las pomposas relaciones y los coros a cuatro voces ${ }^{31}$.

Su triunfo, que ha de esperar la temporada 1805-1806, que es, además de tardío y efímero, relativo y limitado a unas pocas obras y casi un solo autor, Leandro Fernández de Moratín, encuentra incluso cierta justificación en su aproximación a la comedia lacrimosa, en su parcial heterodoxia. Así lo ve Mariano José de Larra:

Moratín ha sido el primer poeta cómico que ha dado un carácter lacrimoso y sentimental a un género en que sus antecesores sólo habian querido presentar la ridiculez ${ }^{32}$.

Mas las paradojas no acaban aquí, pues de la batalla iniciada en torno a las reglas y a nuestro teatro «nacional» a mediados del XVIII, herido nuestro orgullo con el «qqué ha hecho España por Europa?», nacerán dos bandos: el de los «clasicistas» y el de los «anticlasicistas» -el último de los cuales será luego en cierto modo relevado por los «modernos»-, que, esgrimiendo el patriotismo, tratarán a sus rivales siempre de antinacionales y extranjerizantes ${ }^{33}$. El antiextranjerismo,

antiguas virtudes que, según su punto de vista, hicieron la grandeza del país bajo los Austrias. Virtudes que la Filosofía pugna por desterrar, y cuya cátedra es Calderón: propagarlas es la verdadera Ilustración, en contra del cosmopolitismo francés, enemigo de las peculiaridades nacionales».

31 Ramón de Mesonero Romanos, «Rápida ojeada sobre la historia del teatro español. Epoca actual», Semanario Pintoresco Español, Segunda Serie, 1842, IV, en Ricardo Navas Ruiz, El Romanticismo español-Documentos, Anaya, Salamanca, 1971, p. 304.

32 «Primera representación de El sí de las niñas», en Artículos de crítica literaria y artística, 7. ${ }^{\text {a }}$ ed. Clásicos Castellanos, Madrid, 1975, p. 114, donde un poco más adelante nos dice: «[...] parece que se complace con amargura en poner a la boca del precipicio a su protagonista [...] o en hundirle en él cruelmente [...]. Un escritor romántico creería encontrar en esta manera de escribir alguna relación con Víctor Hugo y su escuela, si nos permiten los clásicos esta que llamarán blasfemia.»

33 Por no extendernos demasiado, ilustramos tan sólo la menos frecuentemente considerada postura patriotera del bando clasicista con las siguientes palabras de José Joaquín de Mora, «Artículo comunicado», Mercurio Gaditano, n. ${ }^{\circ}$ 143, octubre 
principalmente antigalicismo, encuentra además profundas raíces sociológicas (desde la competencia en el comercio hasta la influencia en todos los aspectos de la vida cotidiana), religiosas (llegándose a equiparar la Revolución con la Reforma) y políticas. Paradójicamente, aun nuestro conato de revolución coincide con la lucha contra el francés, ideólogo del movimiento liberal español. Y llevando todo este rompecabezas al teatro, Mariano José de Larra podrá exclamar con sarcasmo:

Dichoso el país [...] donde no puede hacer efecto una comedia escrita contra la aristocracia, por ser en el tal país la aristocracia la primera liberal ${ }^{34}$.

El público, en cambio (el pueblo, insistimos, ya que no existe sistemática diferenciación de clases en los coliseos), si no ajeno a estos planteamientos en otros dominios, acude al teatro a divertirse sin discriminar los productos importados mientras se ajusten a sus preferencias ${ }^{35}$. Es más, cercano ya el triunfo romántico, él es el verdadero afrancesado $^{36}$. Y mientras en nuestro suelo siguen los poetas empeñados en imponer un teatro arreglado que no encuentra eco, el pueblo manifiesta un gusto ya romántico que han ido cimentando las traducciones.

No es válida, sin embargo, para todo este período, la frecuente afirmación de que se recurrió a las traducciones porque, siendo menos laboriosas que la creación de obras originales, proporcionaban mayo-

1814: «Este espíritu es para la poesía lo que para la guerra: un ilustrado patriotismo lo suple con ventaja, como lo experimentaron la Grecia y Roma. Los prodigios recientes de los españoles que se hallan hoy tan distantes de aquellos tiempos romancescos, tienen en su patriotismo, en el honor nacional, que es de todos los tiempos en España, y en el odio a la dominación extranjera, igualmente que en su pasión decidida por su siempre perseguido y afligido Fernando VII, una explicación más obvia, más natural y más noble que en el espíritu quijotesco y de caballería, cuya aplicación se haría más verosímil a las aventuras y desconcertadas empresas del caballero de Córcega, Napoleón». En R. Navas Ruiz, op. cit., p. 26. En «Imperio y virtud, o el seductor confundido», BAE, 127, p. 397.

35 No nos sorprende, por tanto, como a Ramón Solís, el criterio de los críticos teatrales gaditanos, que lógicamente responde a principios ilustrados: «Estas críticas no aparecen, como fuera de esperar, ante los fracasos rotundos. En su mayor parte son una reacción contra el aplauso que se consideraba injusto. [...] El criterio de los comentaristas teatrales no siempre es digno de tenerse en cuenta, ya que ni Lope ni Calderón se libran de sus ataques». El Cádiz de las Cortes, Alianza, Madrid, 1969, p. 359.

36 «El público, más que los autores, sufría un fuerte afrancesamiento cultural [...]. No iba al teatro si no veía propagandadas como francesas las obras en cartel.» P. Menarini, «El problema de las traducciones en el teatro romántico español», VII Congreso de la Asociación Internacional de Hispanistas, Venecia, 1980, p. 754. 
res ingresos ${ }^{37}$. Y es igualmente exagerada la descalificación general que de los traductores hace también Larra -comúnmente aceptada—, quizá adverso, sobre todo, al tipo de obras que se traducen y que no puede admitir desde su primera actitud netamente clasicista ${ }^{38}$. El papel de las traducciones en el desarrollo del teatro español decimonónico es fundamental en cuanto abastecedoras de un repertorio necesario para la pervivencia con éxito del espectáculo, en cuanto introductoras de temas y formas europeas y, sobre todo, en cuanto ejercicio de formación de nuestros autores ${ }^{39}$. Su frecuencia, además, irá en aumento durante la primera mitad del siglo, pudiéndose establecer que de un tercio, aproximadamente, durante las dos primeras décadas, se pasaría a lo menos un cincuenta por ciento durante las dos siguientes ${ }^{40}$. Tal progresivo aumento -que, como apunta P. Menarini, es difícilmente atribuible a la desaparición de la censura o al desarrollo de la industria editorial-, parece apuntar más que a motivos sociopolíticos a razones de necesidad artística, según señala Larra:

Posteriormente la traducción fue entre nosotros una necesidad: careciendo de suficiente número de composiciones originales, hubo de abrirse la puerta al mercado extranjero, y multitud de truchimanes con el Taboada en la mano y valor en el corazón se lanzaron a la escena española ${ }^{41}$.

Necesidad de renovación escénica que se acentúa con la aparición del melodrama que, como género que se basa en el «coup de théâtre» y la peripecia del protagonista, ha de renovarse continuamente, lo que se advierte en la escasa duración en cartel de estas obras. Ello lo corrobora el hecho de que la recensión crítica de estas representaciones recoja por extenso - y casi exclusivamente - el desarrollo de sus argumentos, lo cual debió de tener, por otra parte, no poca importancia en la difusión de sus contenidos.

La profunda transformación de las mentalidades que debió de ejercer el teatro durante esta época - y la paulatina evolución de la

Vide Ch. M. Lorenz, «Translated plays in Madrid Theatres 1808-1818», Hispanic Review, 9 (1941), pp. 376-382.

38 Así, R. de Mesonero Romanos, en el art. cit., p. 303, nos dice: «... Las traducciones de los modernos repertorios francés e italiano eran diarias y hechas ya con buen gusto en lafelección y esmero en el desempeño.»

39 Así lo ve Menarini, art. cit., p. 572, quien señala que por ellas pasaron todos o casi todos los autores luego aplaudidos.

40 Ello sin contar las obras aún consideradas anónimas ni piezas musicales, que según Ch. M. Lorenz, completarían un 50\% para los años 1808-1818. Cf. art. citado, p. 378.

Para la segunda época aludida, véase P. Menarini, art. cit., p. 751.

41 «De las traducciones», BAE, 128, p. 180. 
escena- es fácil de advertir a través de la crítica de Mariano José de Larra quien, como defensor de un teatro ilustrado, propugna un despotismo con muestras de claros convencimientos liberales:

[El teatro es] una diversión que dirige la opinión pública de las masas que la frecuentan; un instrumento del mismo gobernante, cuando quiere hacerle servir a sus fines; una distracción que evita que los ociosos turbulentos piensen y se ocupen en cosas peores; un morigerador, en fin, de las costumbres, que son en nuestra opinión el único apoyo sólido y verdadero del orden y de la prosperidad de un pueblo.

[...] Estamos seguros de que el interés es el gran móvil del hombre; toda la dificultad está en hacerle conocer cuál es su verdadero interés. Esto se lo proporciona la sólida instrucción, que es la única de que hablamos: en este caso, ésta será en todo y por todo para el hombre el manantial de su felicidad ${ }^{42}$.

Es lógico, pues, que desde esta perspectiva no pueda ser admitido el melodrama, que ni es espejo de buenos modales, ni ejemplo de lenguaje y estilo virtuosos:

[...] El colorido de sublimidad y pasión que en el teatro suelen revestir los vicios y los crímenes no sería el mejor medio de hacerle al hombre escarmentar ${ }^{43}$.

Obviamos, sin embargo, sus frecuentes diatribas contra este género que «hace llorar como haría llorar a cualquiera una paliza; horroriza, espanta, asombra, estremece, horripila» ${ }^{44}$. Frente a él, defiende nuestro crítico la comedia ilustrada, reflejo y ridiculización de costumbres y defectos sociales, o incluso el «vaudeville» de su admirado -y traducido- Scribe, que tiene la ventaja frente al entremés de no «halagar casi siempre las costumbres de nuestro pueblo bajo, por los términos en que está generalmente escrito ${ }^{45}$.

Ya ha sido debatida repetidas veces la frecuentemente contradictoria posición de Larra con respecto al Romanticismo (¿ecléctica?) como para que nos atrevamos desde esta limitada perspectiva a tomar cartas en la discusión ${ }^{46}$. Con todo, y ateniéndonos a referencias concretas,

42 «Reflexiones acerca del modo de hacer resucitar el teatro español», BAE, 127, p. 123-124.

43 «Teatros», BAE, 128, p. 157.

44 «El verdugo de Amsterdam», BAE, 127, p. 395.

45

De las traducciones», BAE, 128, p. 180.

46 Creemos que Azorín da en el clavo (y disipa las sombras con que él mismo se topa en relación con la actitud de Larra respecto a Anthony) cuando al tratar de su carácter lo define como «un espíritu de rebeldía» que evoluciona con el cambio de las circunstancias. No se puede esperar desde esta perspectiva - pensamos - una 
nos parece indudable que los acontecimientos políticos y sociales le conducen a una revisión de sus principios estéticos y morales que le lleva a admitir la violencia y el horror como más fiel representación de la realidad que la suave visión proporcionada por la comedia neoclásica:

En cuanto a los medios y las formas dramáticas, a los crímenes, a los horrores que han sucedido en el teatro moderno a la fría combinación de las comedias del XVIII, oponerse a ellos es oponerse a la diferencia de las épocas y de las circunstancias, con las cuales varía el gusto. Al teatro vamos a divertirnos, dicen algunos candorosamente. No; al teatro vamos a ver reproducidas las sensaciones que más nos afectan en la vida; y en la vida actual, ni el poeta, ni el actor, ni el espectador, tienen ganas de reírse; los cuadros que llenan nuestra época nos afectan seriamente, y los acontecimientos en que somos parte tan interesada no pueden predisponernos para otra clase de teatro; de aquí que no se darán comedias de Molière y Moratín, intérpretes de épocas más tranquilas y sensaciones más dulces, y si fuera posible que se hicieran, no nos divertirían ${ }^{47}$.

No irá, sin embargo, tan lejos como para aceptar la visión nihilista del mundo, de la familia, de las posibilidades de promoción social del pueblo bajo (el inclusero de Anthony), que de forma trágica nos presentan las obras de una etapa avanzada del Romanticismo que caracteriza la estética del fracaso, la expresión del desengaño de los ideales políticos y sociales que ni una revolución logra hacer triunfar. $O$ al menos, no llega tan lejos con su literatura, que por pública es ejemplar.

\section{Una colección facticia de obras traducidas}

Ocupa nuestra atención en este último capítulo un conjunto de siete obras traducidas entre 1791 y aproximadamente 1840 , recogidas en un volumen encuadernado en Salamanca, cuya amable cesión agradecemos a nuestro querido amigo y compañero Luis Alcalde Cuevas, a quien debemos igualmente un sinfín de atinadas sugerencias ${ }^{48}$. Punto

coherencia estática ni una evolución en sincronía perfecta con los acontecimientos. Se producen los lógicos desajustes, desfases, que se solucionan luego en nueva

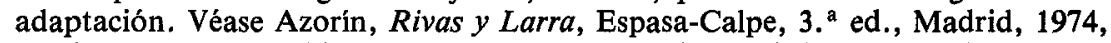
pp. 95 y 142 . Este problema - así como otros muchos- de la personalidad de $\mathrm{Ma}$ riano José de Larra se plantea igualmente en el excelente estudio de José Luis Varela Larra y España, Espasa-Calpe, Madrid, 1983.

«Catalina Howard», BAE, 128, p. 186.

Encuadernada por Bonifacio López (sin fecha) bajo el título de «Comedias Varias», la más antigua resulta ser Los amantes desgraciados, editada en 1791, y probablemente la más moderna Está loca, a la que le falta la portada. Una anotación manuscrita en la página anterior señala como fecha de lectura el 21 de abril de 1842. 
de partida de nuestras reflexiones, queremos ahora comentarlas brevemente, tanto por su valor ilustrativo de las características que hemos venido señalando, como por haber determinado algunas de ellas significativas reacciones que tratamos de apuntar.

Bruto, o Roma libre es la obra que abre nuestra colección. Tragedia en cinco actos de Alfieri - a quien no se cita en la portada-, traducida por Antonio Saviñón, la imprime en Valencia Domingo y Mompié en $1820^{49}$.

Estrechamente ligada por su carga ideológica y su estilo de arenga popular al acontecer político español, se puso en escena y publicó en Cádiz en 1812 para celebrar la nueva Constitución, precedida de un prólogo en verso que en nuestra edición no consta, pero que queremos recordar:

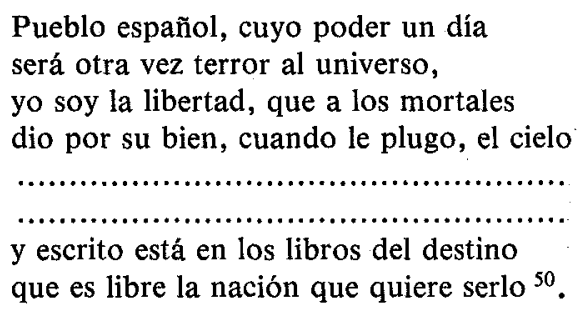

Dos años más tarde se representó en Madrid -aunque no se publicó en Madrid hasta 1820 - así como en enero y mayo de $1836^{51}$. Obra esmeradamente traducida en versos endecasílabos con asonancia en los pares y variación de rima en cada acto, aunque no encaja estrictamente en ninguno de nuestros apartados anteriores, posee una serie de características comunes con los géneros descritos que justifican en parte su relativo éxito ${ }^{52}$. Se trata, en efecto, de una tragedia «arreglada», que si

49 Raras veces aparece el nombre del autor en las obras del período que nos ocupa, 10 que dificulta aún más su estudio. Con frecuencia, además, el nombre del traductor se oculta bajo un seudónimo, sobre todo antes del 30 - según Menarini-, como prueba de una tarea en un principio no excesivamente honrosa.

Citado por A. Peers, op. cit., vol. I, p. 320.

51 Vide A. Peers, op. cit., vol. I, pp. 317-321, y «The vogue of Alfieri in Spain», Hispanic Review, 1933, I, pp. 122-140; La Esperanza, 1-1-1836, y La Gaceta de Madrid, 29-1-1836. El C. S. I. C., en su Cartelera teatral madrileña (1830-1839), Cuadernos Bibliográficos-3, Madrid, 1961, señala las representaciones de los días 4 y 5 de enero y 1 de mayo de 1836.

52 Creemos que es notorio también su parentesco en muchos de sus principales aspectos con La Numancia cervantina, ya que, igualmente, aprovecha los acontecimientos políticos para llegar a la escena de la Zaragoza sitiada por las tropas napoleónicas. 
no es lícito - como precisa Peers a Cotarelo- calificar de prerromántica, comporta una exaltación de la libertad y de la igualdad, un patetismo melodramático y un efectismo teatral que la acercan mucho a la nueva estética. Obra histórica con movimiento de multitudes en escena, culmina en el momento en que van a caer las cuchillas que decapitarán a los traidores. Entre ellos, arrepentidos, los hijos de Bruto, que con su traición trataban de salvarlo. Es el triunfo de la ley sobre la tiranía, el triunfo del pueblo, a cuya cabeza Bruto, sobre los patricios que, «a la sombra pestífera creciendo/de la corte falaz en ocio muelle,/el ocio dulce engañador bebieron/de la vil tiranía» (acto V, escena $1 .^{\mathrm{a}}$ ). Tarquino es además un rey extranjero: «...los tiranos/no tienen patria, no, ni la merecen:/y menos la merecen los extraños,/que, cual él, de extrangeros descendiendo,/vinieron a reinar entre Romanos:/su honor ha largo tiempo que ellos mismos/con su vil proceder arrebataron» (acto II, escena $6 .^{2}$ ). Oigamos, por fin, dos extractos de discursos del final del primer acto, con que queremos subrayar las concomitancias con la situación española, especialmente de Cádiz en 1812:

\section{BRUTO}

Nada, nada jamás debe ocultarse de un pueblo soberano en el Congreso.

hondo terror en sus acciones puso.
Hoy de alta gloria y de grandiosos hechos
a la contienda ilustres por vosotros
convocados serán: y en breve tiempo
reunidos aquí, cimiento firme
a nuestra excelsa libertad pondremos.

PUEBLO Este es el primer día en que vivimos.

BRUTO Cópielo el mundo y vivirán los pueblos.

Los amantes desgraciados, o El conde de Comminge, drama en tres actos escrito en francés por Mr. D'Arnaud, y traducido al castellano por D. Manuel Bellosartes, Madrid, 1791.

Obra escrita en 1764 por François Thomas Marie de Baculard d'Arnaud, es una de las más interesantes de nuestra colección por cuanto representa una temprana manifestación de aspectos que suelen considerarse románticos. A una trama argumental que insiste en oponer obstáculos a la voluntad de los amantes acompaña una sintaxis pródiga en signos de exclamación, puntos suspensivos, acotaciones que marcan la vehemencia de los sentimientos, el continuo derramamiento de lágrimas y profusión de suspiros. 
Al amor del conde por Adelayda, su prima, se opone el odio de su tío hacia su padre. Encuentros y desencuentros contribuyen a subrayar el poder del destino. Liberado el conde por el hermano del marido impuesto a Adelayda - a su vez enamorado de ella-, creyéndola muerta, ingresa en la Trapa. Adelayda, oculta su personalidad y condición femenina bajo el hábito, decide acabar su vida cavando su propia fosa y llorando su amor desgraciado al lado del conde, que ignora su identidad.

Rencores familiares, lazos sanguíneos, votos religiosos que se interponen, pues, al sentimiento del héroe, para que al fin, muerta ya Adelayda, concluya el autor en los últimos versos del drama:

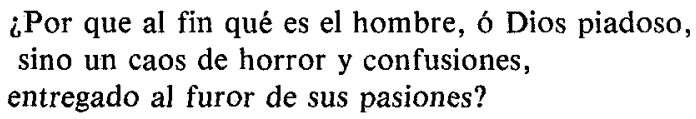

Lo más interesante, quizás, es el triple planteamiento argumental, que contrapone amor, destino y religión. El conde de Comminge no sólo debe enfrentarse a los obstáculos que a la realización de su amor se ofrecen sino, posteriormente, a su propia conciencia religiosa, a la voz misteriosa de Rancé, el fundador de la Cartuja, que desde la tumba le reprocha sus deseos. De este último conflicto, de la lucha consigo mismo, es de donde nace su carácter romántico, atormentado, apasionado, su esencia trágica.

La obra, compuesta de largos parlamentos, con frecuencia con resonancias de nuestros clásicos - quizás Calderón sobre todo-, anticipa también conocidas escenas del romanticismo español:

Soñaba yo que erraba medio muerto por las lóbregas sendas de un desierto cuyo bosque sombrío e intrincado estaba de sepulcros rodeado. Del fondo de estos negros monumentos salían a millares los lamentos, y exhalaban por todas sus junturas errantes sombras, pálidas figuras. Ecos tristes y fúnebres acentos ocupaban los campos y los vientos: pero más mi aprehensión horrorizaban los cráneos que hasta el cielo se elevaban;

A la luz, pues, de una vela sangrienta una infeliz mujer se me presenta, enlutada, afligida, inconsolable, sucumbiendo a una muerte inevitable.

Me acerco a socorrerla... ¡O Dios! ¿Qué es esto?

Adelayda... Adelayda... a tus pies puesto... voy ansioso a abrazarla... y quando creo 
cumplir entre mis brazos mi deseo;

hallo, para escarmiento, entre mis brazos

de espectros y atahudes los pedazos.

(Acto III, escena 1. ${ }^{\text {a)}}$

Sin intentar resolver aquí si se trata de una muestra del «primer Romanticismo» - problema que ya tratamos anteriormente-, nos interesa, al menos, insistir en la difusión que este tipo de obras tuvo en España. Lafarga Maduell, en su trabajo inédito El teatro francés en España desde 1700 hasta el Romanticismo, señala aún traducciones de esta obra en Barcelona, 1792; Barcelona, 1820; y otra sin lugar ni fecha ${ }^{53}$. No queremos, sin embargo, dejar de señalar que, como advierte Menarini en su artículo citado, sería difícil establecer una estricta correspondencia entre la proliferación de las traducciones y el éxito escénico de las obras, siendo plausible la existencia de dos mercados paralelos, e incluso independientes ${ }^{54}$. Esta traducción, además, da la impresión de haber sido realizada con miras a la lectura por el prólogo argumental -en prosa- que nos cuenta la desgraciada historia del conde, situando el drama en su entrada en el convento de la Trapa. No tenemos noticia de si llegó a representarse y no consta en la Cartelera antes mencionada del C. S. I. C. Su destino original, al menos en Francia, fue desde luego el de la representación, ya que se basa en una novela de idénticas características y con cuya última parte coincide el argumento. La fecha de edición de la novela es de capital importancia por cuanto da al traste con el «primer Romanticismo» o la «première vogue romantique», al menos cronológicamente, ya que aparece en 1735.

¡Está loca! es obra de la que nos da cuenta Larra en los siguientes términos: «Es parto de la imaginación de M. Melesvilles, uno de los vaudevillistas más furiosos y sentimentales de París, y fue representado por primera vez en enero de 1835.»Y algo más adelante: «llamólo el autor comedia; y el traductor, mucho más entendido que aquél, al dejar todo el lance en francés, mudóle sólo el género» ${ }^{55}$. Se representó en Madrid del 14 al 16, el 19 de junio, el 8 de agosto y el 9 de diciembre de 1836. Lafarga Maduell no cita traducciones de esta obra, aunque sí de otras de Melesvilles en colaboración con diversos autores. En el diario El Español del 17 de junio de 1836 aparece una larga reseña en que se recoge por extenso su argumento, que brevemente resumimos:

53 Trabajo patrocinado por la fundación J. March, 1980, en cuya biblioteca puede consultarse. No citamos página por tratarse de un índice alfabético.

54 Art. cit., p. 758.

55 «Está loca, drama en dos actos...», BAE, 128, pp. 232 y ss. 
Sir Harleigh cree haber matado al amante de su esposa, Sir Maxwell -quien en realidad visitaba a su esposa Nelly, sobrina de aquél, con la que contrajera matrimonio secreto-. De remordimientos pierde el juicio. Desde entonces el hogar se vuelve una pesadilla, especialmente para Lady Ana, a quien Sir Harleigh atribuye su propia locura, y de la que se ocupa el doctor Yollack, que pronto identifica al verdadero enfermo. Wilkins, sobrino de Sir Harleigh, en razón de la demencia de éste, pretende su fortuna, por lo que se hace acompañar del juez de paz, que resulta ser Sir Maxwell. La sorpresa del inesperado reencuentro, añadida al excelente tratamiento "psicoanalítico» del doctor, trae de nuevo la cordura y la felicidad al hogar.

Como se puede fácilmente advertir, a pesar de la descalificación de Larra, se trata de una comedia urbana de escasa imaginación y muy poca furia y sentimentalismo (lo que no añade nada, por otra parte, a su mínimo valor literario). Es ella realmente - Lady Ana- la protagonista, la virtud resignada: «homo homini agnus». El grupo familiar, incompleto por la ausencia (mental) del patriarca y del yerno, se reúne a la postre con el sobrino envidioso (al que se le hace partícipe del final feliz con el generoso donativo de una finca) y el bondadoso doctor, para juntos posar sonrientes ante el complacido público. No falta ningún tópico, aunque la obra no vaya tampoco más allá. El desgraciado Maxwell del principio, ausente de su amada y clandestina esposa, exclama:

Ah! imposible! por más que desafío los riesgos, los peligros, siempre salgo bien de ellos. Deseo la muerte, Wilkins. (Acto I, escena 4. ${ }^{\mathrm{a}}$ )

La exaltación de la burguesía recae en un personaje más filántropo que el comerciante, el médico, que concluye:

No me deis las gracias, hijos míos... Hay momentos en que es muy dulce el ejercicio de mi profesión. Ahora soy el más dichoso del universo. He vuelto la salud a un amigo... la felicidad á una familia entera... Y al contemplar mi obra, diré con orgullo, con satisfacción: Los he librado de una desgracia. He evitado las consecuencias de un error... Hé aquí mi recompensa. (Ultima escena del II y último acto.)

Y para no olvidar nada, la ambientación londinense, típico sello de origen del producto.

Los dos sargentos franceses. Drama de espectáculo en tres actos arreglado a la escena española por D. J. M. de C. Representado en el Coliseo del Príncipe. Madrid, Imprenta de Repullés, $1830^{56}$.

Les deux sergents es obra de Théodore Baudouin d'Aubigny y

56 La iniciales de la portada corresponden a las de don José María de Carnerero, famoso traductor de la época que en nuestra colección es también el autor de otra versión, la de El pobre pretendiente, de 1831. Por la proximidad de las fechas no podemos suponer que en este caso se trate de ocultamiento de la personalidad por el desprestigio de la labor. 
Auguste Maillard y se representó en París en 1823. No debió de alcanzar gran éxito en nuestro país, ya que no se conocen otras ediciones ni representaciones que las indicadas. En resumen, el asunto de la obra es el siguiente:

En Port Vandré el ejército francés ha establecido un cordón sanitario con el objeto de impedir el tránsito de los catalanes españoles afectados por la peste. Cediendo a la compasión, los sargentos Félix y Roberto dejan pasar a una pobre mujer que con sus hijos viene de Zaragoza, zona no contaminada. Denunciados, la sentencia es una sola condena de muerte. $\cdot$ La suerte en los dados favorece a Roberto, enamorado de Laureta (que también pretende el ayudante mayor Moraci), pero se ofrece para sustituir a su amigo mientras se cumple el plazo, de modo que pueda Félix visitar a su mujer e hijos, a los que no ve desde hace tiempo (pues, aunque inocente, había sido anteriormente acusado de robo y degradado y, por evitar la deshonra familiar, venía ocultando desde entonces su auténtica personalidad). Moraci intenta impedir el regreso de Félix para que en su lugar sea ejecutado su rival Roberto, mas el fiel amigo se arroja al mar y logra alcanzar la playa en el preciso momento y lugar en que se iba a cumplir la sentencia. En el último instante llega el indulto, el reconocimiento del antiguo error de la justicia para con Félix - al que se nombra coronel-y el arresto de Moraci.

A pesar de la proximidad de la presente obra con la anteriormente comentada, saltan a la vista las diferencias de sus respectivos géneros. Del ambiente urbano, familiar, pasamos a una escenificación variada, espectacular (la prisión en el primer acto; la isla de Rosas, donde vivía la familia de Félix, en el segundo; la playa de la ejecución en el tercero). La intriga se desarrolla articulando inverosimilitudes o incongruencias: la condena, la partida de dados, la fortuna que hereda la mujer de Félix, la ola oportuna que arroja el cuerpo del capitán deshonrado en el momento exacto..., y que revelan la acción de una Providencia que siempre en última instancia, justiciera, premia y castiga. El drama se organiza en torno al «suspense» de la pena que (como en Roma libre, Guzmán el Bueno...) recae sobre un inocente o un delincuente piadoso. En la obra se da entrada a partes musicales y a danzas (de lugareños, en el encuentro de Félix con su familia). Félix representa perfectamente, además, la virtud perseguida y resignada, ya que es víctima inocente de la justicia, y es en su persona en quien culmina la admiración final de la virtud con la identificación explícita y la exposición moral:

$R O B$.

¡Oh Dios! ¿Qué oigo?... Y ese capitán Dervil... ese modelo de generosidad, de valor y de constancia; ése... ioh felicidad!... yo no puedo contenerme... ése le tenéis en vuestra presencia... ése es el sargento Félix!...

Varias voces ¡Félix!

Otras ¡El sargento Félix!...

FEL. Sí... el mismo soy... El cielo en un instante borra todos los tormentos que se han sufrido, y en su infinita clemencia nos abre el puerto 
de la esperanza y de la fortuna. Mi historia os será conocida. Vamos ahora á elevar nuestra gratitud al Todopoderoso; á tributársela al Soberano por el conducto de nuestro dignísimo general; y combatiendo en favor de la tranquilidad pública y de la augusta dinastía de los Borbones, háganse dignos del aprecio de sus compatriotas, del amor de sus familias, y de los elogios de la posteridad Los dos sargentos franceses.

(Fin de la obra.)

Treinta años, o la vida de un jugador. Melo-drama de espectáculo en tres actos. Nuevamente traducido y arreglado al teatro español por Zelmiro. Barcelona, 1829 ,

Obra de Víctor Ducange, uno de los autores más importantes del género, fue editada por primera vez en Barcelona en 1828, en traducción de Nicasio Gallego, y reeditada al año siguiente. Lafarga Maduell recoge la traducción de otras nueve piezas de Ducange.

Treinta años fue una de las obras de más éxito, incluso ya alcanzado el «triunfo» del Romanticismo español ${ }^{57}$. A su representación en Madrid dedica Larra el artículo «Una comedia moderna», en el que su inteligente humor no llega a disfrazar su rígida postura neoclasicista inicial y un cierto antifrancesismo ${ }^{58}$. La obra (cuyo argumento y escenificación relata Larra con enorme ironía en el artículo citado) es un melodrama casi prototipico. Los personajes, sin profundidad psicológica alguna, se reparten maniqueamente entre el jugador (que llega a la máxima degradación) y su víctima, su resignada esposa (redimida al fin por su hijo). Los caracteres de la antigua comedia se simplifican en la pluma de Ducange, escritor de «boulevard»; las acciones se elementalizan para tratar de sobrecoger al espectador con terribles escenas que, a través de un lenguaje sencillo, recalcan el mensaje moral del autor.

Amelia, huérfana desde los diez años, amable, sentimental - como nos la describre el perverso Warner, amigo de Jorge, el jugador-, va a ser engañada y sacrificada desde la primera escena. A Jorge, ya también desde el principio, se le anuncia el desprecio, el des-

57 En la Cartelera ya citada del C. S. I. C. se señalan las siguientes representaciones en Madrid: 1831-IX, 16-20; 1832-I, 8,21,22; 1833-VI, 30; 1834-X, 2,5; 1835-VII, 27,28; XI, 24,25; 1836-I, 9; IV, 22.

Mariano José de Larra, Artículos de crítica literaria y artística, Espasa-Calpe, Madrid, 1975, pp. 1-19. Un breve extracto nos sirve para ilustrar el comentario y situar la obra: «... mais nous, que hemos introducido en el parnaso el melodrama anfibio y disparatado, lo que nunca hubieran hecho los españoles; mais nous, que tenemos más orgullo que literatura; mais nous, que en nuestro centro tenemos a todo un Ducange, que nos envanecemos de haber producido La huérfana de Bruselas, Los ladrones de Marsella, La cieguecita de Olbruc, Los dos sargentos franceses, etc.》 (pp. 17 y 18). 
honor, la miseria y el crimen a que conduce el juego. Lo demás será una serie de inverosimilitudes e incongruencias que se complace Larra en subrayar, de cambios de escenario y transcurrir de años, de «tamboril y gaita gallega» y truenos y relámpagos hasta la última y más dramática escena en que Jorge va a matar (con Warner) a su propio hijo sin reconocerlo, mientras la pequeña hermana de ocho o diez años nos sirve de contrapunto sentimental. Para colmo, la Providencia resuelve el desenlace descargando un rayo sobre la choza, a lo que añade Larra con sorna: «en toda nación bien gobernada se debería usar en lugar de pararrayos un par de jugadores» ${ }^{59}$.

Pero prescindiendo un poco de los caracteres de esta obra, que por más conocida podemos soslayar, nos interesa insistir en su recepción. Aunque aplaudida, La vida de un jugador pertenece a un género que aún resulta relativamente nuevo en España, como demuestra el hecho de que Larra precise presentarla:

Esta pieza melodramática pertenece a un nuevo género de poesía que no fue del tiempo de Horacio [...] Esta es la poesía romántica, objeto de una gran disputa que hay en el día en el Parnaso ${ }^{60}$.

Lo que Larra rechaza de la nueva estética es su falta de respeto a las reglas y su violencia y, por consiguiente, falta de ejemplaridad. Pero he aquí que en 1833 , sólo cinco años más tarde, poco antes del triunfo del Romanticismo español, nos dice:

[...]Embotadas, en fin, las sensaciones de los hombres de nuestra época por la funesta sucesión de revoluciones políticas y grandiosas que han trastornado en nuestros tiempos el orbe, érales preciso a los ingenios tomar una senda nueva, que, dando paso a la curiosidad o punzando fuertemente nuestra irritable cuanto gastada sensibilidad, llenase los exigentes deseos de un público cansado ya de dejarse conducir, al compás monótono de las reglas, por un campo sembrado de menudas florecillas, olorosas sólo para un olfato delicado. Sensaciones fuertes, ampulosas declamaciones, llantos, desgracias, muertes han sido los medios que han substituido en el teatro a la sal cómica de Molière o a la delicada sensibilidad de Racine. [...] Si alguna cosa hay en el mundo que iguale las clases es la pasión; el corazón, pues, y el sentimiento son las fuentes donde ha de beber el actor su inspiración ${ }^{61}$.

Su aceptación crítica, como se ve, no se ha hecho esperar demasiado. El camino del Romanticismo estaba ya expedito.

El arte de conspirar. Comedia en cinco actos y en prosa traducida del francés por don Ramón de Arriala, Madrid, 1839.

59 Ibid., p. 15.

60 Ibid., p. 2.

61 «Primera representación de La extranjera», ibíd., pp. 47-49. 
Bertran et Raton ou l'Art de conspirer, comedia de Scribe, uno de los más afortunados dramaturgos franceses en nuestra patria - llegó a ver traducidas y representadas en España medio centenar de obras-, se estrenó en París el 14 de noviembre de 1833. Fue traducida en 1835 por Larra y se publicó en esa fecha con el anagrama que en nuestra edición consta. Ignoramos si la versión del 35 difiere en gran medida de la presente, que mantiene el nombre de Berton para el comerciante, María Julia para la reina y sitúa la acción en Copenhague ${ }^{62}$. Se estrenó en Madrid el 17 de enero de ese mismo año de 1835 y volvió a representarse con el éxito propio de Scribe en los años siguientes ${ }^{63}$.

La comedia, que en España se anunció con el más propagandístico subtítulo de El arte de conspirar, había agradado al público francés de los diferentes teatros parisienses precisamente por su carga ideológica conservadora, de desencanto revolucionario. Muy bien entretejida, con gran acierto en la caracterización de los personajes y un animado diálogo, debió su éxito probablemente más a la habilidad y maestría de Scribe en lograr un lenguaje auténticamente dramático, que a los recursos y temas típicos del Romanticismo entonces en boga, que apenas tienen cabida en su producción. Aún habría que añadir que quizás esta avanzada fecha de composición (1833) justifique la visión desilusionada e irónica que el dramaturgo nos ofrece de muchos de los temas hasta entonces preferidos y el enfoque «racional» del mundo que ello supone (y que lo apartaba de la estética romántica, si bien no del favor del público): el ridículo comerciante, el astuto y cínico conspirador, el estulto agitador y la aún más necia masa revolucionaria, los ingenuos enamorados, la nueva estructuración social y sus posibilidades de promoción: prestación de servicios al poderoso, servilismo, favoritismo, etc. Pero aunque es sin duda una de las mejores obras de nuestra colección, es tal vez la que menor interés nos ofrece desde los objetivos que nos hemos planteado.

El pobre pretendiente. Comedia en un acto arreglada al teatro español por don José María de Carnerero, Madrid, 1831.

Esta fue la primera versión de la comedia Le solliciteur, ou l'Art

62 P. Menarini cataloga la traducción de Larra en un segundo grupo, el de las no literales, y le atribuye el trasladar la escena a Madrid, el españolizar los nombres de los personajes y poquísimas interpolaciones. Art. cit., p. 756. La crítica de la obra que aparece en la Revista Española el 23 de enero de 1835 le atribuye igualmente algunas modificaciones.

63 Según la Cartelera del C. S. I. C.: 1836-II, 4,11,28; 1837-V, 6,8; VII, 2,3; IX, 1,2; 1838-II, 21,22; III, 4; 1839-IV, 27,29; XII, 7,9; 1835-V, 3,4; VI, 28,29; VIII, 29; XI, 4,8; XII, 9,27. 
d'obtenir des places (1817), también de Scribe, que se había estrenado en mayo de $1830^{64}$. Ridiculiza al aspirante a un empleo, don Verecundo Corbeta y Luenga Vista, que, tratando de engañar a un pobre oficinista meritorio, por error le consigue el puesto que él mismo pretendía. En lenguaje preciso, popular y lleno de gracia, traza así la caricatura de este prototipo de los solicitantes:

Madruga más que el alba, y hasta á los mismos porteros de las secretarías les infunde un terror pánico. No hay agente de negocios que no visite; abogado con quien no consulte; covachuelista á quien no acometa; gentil hombre á quien no salude; consejero á quien no escriba; ministro á quien no apure. Está en todas partes: en los consejos, en las escribanías, en las secretarías, en las antecámaras de todos los grandes. [...] Ni le acometen los resfriados, ni teme la escarcha, ni le detienen los lodos; y es capaz él solo de desafiar á todas las estaciones y á todos los elementos, antes que faltar un minuto á la hora de las audiencias. Sus bolsillos son un almacén de memoriales, su boca un torrente de palabras, su cuerpo un manequin de cortesías, y sus piernas, en cuanto á agilidad, son superiores á las de las liebres. En una palabra, es un hombre que corre, vuela, se enhebra por el ojo de una aguja, no sosiega un instante, se produce y se reproduce con increible ligereza... (Escena $4{ }^{a}$ )

Mariano José de Larra nos señala este mismo tipo social como uno de los más importantes de su época: «Entre las pestes pudiéramos citar la de empleados cesantes, jubilados y pretendientes, como la mayor $"{ }^{65}$. Y Mesonero Romanos, al relatarnos una escena en la que el pretendiente, de forma semejante, «fue a trasquilar y salió trasquilado», relaciona el problema con la situación económica madrileña, su falta de industria, la escasez de propietarios, la pobreza comercial, etc., en paradójico contraste con el lujo de la capital; y termina:

[...] esta terrible manía [la «empleomanía»], es la que despuebla nuestros campos y nuestras fábricas, al mismo tiempo que hincha de pretendientes las antecámaras y las oficinas ${ }^{66}$.

Y esta situación que Mesonero retrata en 1832 fue en aumento, de modo que, en «nota final», «el autor encuentra hoy extremadamente pálidos los colores que empleó entonces para pintarla» ${ }^{67}$. Y luego, en «El pretendiente», de la serie II de las Escenas matritenses, tras seguir

64 La Cartelera del C. S. I. C. recoge las siguientes representaciones: 1830-V, 30; XI, 28,29; XII, 23; 1832-V, 9,10; 1833-VI, 26,30; VII, 1; 1834-VIII, 14; XI, 9; 1835-II, 8 ; 1836-VIII, 8; 1838-VI, 3,4; XII, 30,31.

Fue igualmente repuesta en años muy posteriores: 1844-XI, 6,10; XII, 3; 1846-IX, $8,10,20 ; 1847-I, 31 ; 1848-I V, 26$.

«Teatros», BAE, 128, p. 159.

66

«Pretender por alto», Escenas matritenses, I, BAE, 199, p. 66. 
la importancia de esta enfermedad social, traza un retrato histórico del personaje según los diferentes tiempos, en el que comenta:

Pero el prototipo de la época en cuestión [se refiere al período 1823-33] y la vera efigie del pretendiente veterano era don Verecundo Corbeta y Luenga Vista, cuya animada historia ocupó ya el clarín de la fama, y de cuyo dramático desenlace quedan todavía recuerdos en el Nuncio de Toledo ${ }^{68}$.

Si nos hemos detenido en este asunto, es para subrayar el cambio de sentido que en el teatro español se está operando y que ya apunta desde los albores del Romanticismo. Nos enfrentamos ahora, como vemos, a una estética objetivista que coincide en sus fines con las pretensiones neoclásicas de reforma social, pero que ha cambiado de lenguaje $y$ de asuntos preferidos, que se ha popularizado. Una nueva forma que, aunque empalma con la obra de $\mathrm{D}$. Ramón de la Cruz, debe mucho igualmente al teatro de «boulevard», especialmente de Scribe, se abre paso y se adapta a nuevas circunstancias. Al comentar la representación de La nieve, nos dice Larra:

¿Comedia nueva? ¿Traducida? Claro está. ¿Autor? Scribe: eso ya no se pregunta; cosa es sabida. [...] A Dios gracias no hay asesinos, ni traidores, ni puñaladas, ni pistoletazos, ni tiros de ninguna especie ${ }^{69}$.

Se trata del vaudeville, cuya descripción nos da otra vez Larra:

Género de composición dramática puramente francés, fue una mina inagotable; género complexo, verdadero melodrama en miniatura, así participa de la ópera como de la comedia; hijo de las costumbres francesas, bástale su diálogo diestramente manejado y erizado de puntas epigramáticas ${ }^{70}$.

El vaudeville puro no tuvo, sin embargo, éxito duradero a los ojos de Larra, ya que, al adaptarse al gusto español, para agradar a un público acostumbrado más bien al halago social de los sainetes, hubo de renunciar a algunas de sus características principales: la parte musical y la función satírica, la crítica social. Su importancia en la escena española de estos años y en su evolución posterior no fue, sin embargo, nada despreciable, pero es asunto que escapa ya a la pretensión de estas páginas, que intentaban centrarse principalmente en la "prehistoria» de nuestro drama romántico.

Op. cit., «El pretendiente», BAE, 200, p. 229.

«Primera representación de La Nieve», BAE, 127, p. 227.

70

«De las traducciones», BAE, 128, p. 180. 